\title{
Radiohead and the Resistant Concept Album: How to Disappear Completely
}

\author{
Marianne Tatom Letts \\ Bloomington: Indiana University Press, 2010 \\ ISBN: 9780253355706 (HB) \\ RRP: $\$ 60.00$ (USD)
}

\author{
Raphaël Nowak \\ Griffith University \\ raph.nowak@gmail.com
}

In Radiohead and the Resistant Album, American musicologist Marianne Tatom Letts undertakes the task of deciphering the complexity and abstraction of Radiohead's musical world. While many are still debating over how to classify Radiohead in the realm of popular music, Letts identifies their fourth and fifth albums, Kid $A$ and Amnesiac (respectively released in 2000 and 2001), as "experimental' concept albums" (2) that express the band's ambivalence towards capitalism and its own commodification. From a musicological perspective, Letts aims to understand the meaning of Radiohead's lyrics and political messages towards our contemporary capitalist societies. Hence, Letts' purpose is to dig deep into, and understand the nature of, Radiohead's obsession with alienation within modern society, understood as a "post-apocalyptic wasteland" (56). Her textual analysis offers a great insight into one of the most complex bands in the history of popular music, even though she remains too critical towards the band's effort to challenge their own commodification by dismissing their latest efforts to propose an alternative model of music consumption.

Forming in the late 1980s under the name On A Friday, the 5-piece band from Oxford released three albums in the 1990s (Pablo Honey in 1993, The Bends in 1995 and Ok Computer in 1997) that were stylistically coherent, while they were also "adding increasingly complex layers of production effects to an essentially guitar-driven sound" (6). Their immediate success, marked by the hit single "Creep" in 1993, was, paradoxically, not well received by the band itself. The guitarist Jonny Greenwood, for instance, thought that the band was becoming a jukebox by being asked to play the same hit over and over, whereas they wanted to be exploring their creativity. In the meantime expectations about Radiohead grew and both The Bends and Ok Computer anchored them as an alternative rock band. Letts concludes:

Given the enormous pressure under which the members of Radiohead found themselves after the Ok Computer tour, trying to push themselves artistically while satisfying market demands after the success of their previous two albums, one can guess that they might literally have wanted to 'disappear completely and never be found' (79).

It is under these circumstances that Radiohead claimed the control back over their artistic pursuit and released Kid A in 2000. 
Released in 2000, Kid $A$ is an abstract and electronic album that totally disrupts what Radiohead had accustomed their audiences to. Letts inscribes the album in the tradition of a concept album (an album that has a narrative, a character and a plot) but that also resists the conventions of progressive-rock genre. She points out that there is a character that inhabits the ten songs of the album and whom she depicts as a "hopeless, self-negating subject who disintegrates at the midpoint of the album at the moment of his maximum articulation" (45). However, the subject's journey through Kid $A$ addresses concerns about modern society as a whole: "the subject may well be feeling [...] nihilistic, but he is decrying the modern human condition rather than expressing a personal angst" (84). These messages are diffused within the songs' lyrics that bury "[Radiohead's] political leanings and anti-corporate messages in riddles for its audience to solve" (135). Released six months after Kid A, Amnesiac is seen by Letts as the necessary complement to better understand Radiohead's standpoint, as well as to forget the "past trauma" (126) that Kid A represents. It is the "'next life' available to the subject" (110).

Both albums reveal Radiohead's stand towards the commodification of their music within capitalist society. The leader and singer Thom Yorke states:

What frightens me is the idea that what Radiohead do is basically packaged back to people in form of entertainment, to play in their car stereos on the way to work... but then

I should shut the fuck up because it's pop music and it's not anything more than that (43).

Radiohead expresses a similar form of ambivalence towards their audience. Thus, Letts posits the assumption that the band also expresses defiance towards them. For instance, the final lyrics of the song "Kid A" read, "rats and children follow me out of town" which, "could refer to Radiohead's feeling towards its audience, that they will follow the band naively as though it were a magical Pied Piper" (65). In the Pied Piper legend, the children of the town of Hamlin were lured because the inhabitants failed to pay the pied piper for ridding their town of rats. Letts argues that the closing lyrics "c'mon kids" suggest that Thom Yorke won't lead the "kids" (his audience) away.

Despite the effort of the band to create a narrative and denounce the commodification of music, Kid A ultimately did not escape the rule. For instance, the song "Optimistic" was selected by radio stations to become a single. Here lies the contradiction of Radiohead's career, which Letts summarizes as follows: "Radiohead thrives within the very system it purports to seek to destroy" (80). As such, she expresses quite a critical approach of the band's ideological account and this is where Letts' approach reaches its limits. Indeed, some years after Kid A and Amnesiac, Radiohead did attempt to position themselves apart from the commodified distribution of music. For instance, they let their audiences decide on the price they wanted to pay for an online digital copy of their seventh album In Rainbows in 2007. Unlike many other music bands who keep trying to fight the digital phenomenon and those who download their music, Radiohead closed the gap between artist and audiences by letting them decide on what they think music is really worth in terms of monetary value.

As Letts notes, they were then reflecting upon whether the format album itself was dying, and whether they should simply release new tracks as they record them. The book, however, ends before Radiohead released their eighth studio album, The King of Limbs, on CD, as to confirm Letts' claim about the band's commodification. Moreover, this example shows how the digital era of music distribution and consumption is not opposed to material objects and therefore commodification. Instead, music objects that are packaged, promoted and sold to audiences, still hold an important part of a music band's existence, and therefore, career.

Drawing on a musicology perspective, Letts does provide a very detailed and relevant account of Radiohead's music career and ambivalence towards their existence in a capitalist society. However, she may overestimate the band's political standpoint as well as their audience's ability to decipher the messages in Kid A and Amnesiac. 
Thus, Radiohead's artistic world is influenced and shaped by Georges Orwell, Naomi Klein, Slavoj Žižek, while also deeply relying on commodification, business and advertisement. Maybe it is the particularity of Radiohead's approach to the commodification of music that explains how they both raise popularity and defiance, passion and hatred from music audiences. Their message, however, remains essential to decipher. Indeed, "interpreting Kid A becomes a metaphor for surviving in modern society" (94), as if the code to endure the commodifying capitalist society had infiltrated art itself. Ultimately, the story of Radiohead brings the truth into art, whereas Nietzsche considered that art was the way to escape the truth when stating: "we have art in order not to die of the truth" (1882, The Gay Science, book II). Radiohead deconstructs the true meaning of contemporary capitalist societies and communicates it by diffusing it through their art. Art becomes a commodity that conveys the truth rather than enables people to escape it, as to prove that critiques and changes must come from within. 